\title{
Pedagogy of the Connected: new media landscapes and the challenges of journalism education
}

By Muhammad Idrees Ahmad

\begin{abstract}
This article proposes a dialogical teaching paradigm based on Paulo Freire's conception of critical pedagogy. It argues that Web 2.0 technologies are uniquely suitable for such an approach. It moves from theory to prescription. It begins with a survey of the current media landscape and state of journalism. In the light of these, it makes a case for an approach to journalism education in which civic function is complemented by technical proficiency. Based on extant scholarship and the author's experience as a new media practitioner and educator, the article notes the distinctive features of Web 2.0 technologies that make it particularly amenable to such an approach. It focuses on two specific onesBlogs and Wikis - to suggest ways in which the learning experience can be enhanced. But it emphasizes that absent the awareness of journalism's civic function, technical skills may enhance employability, but they won't bring professional respect. To compete in a saturated field, journalists will have to show both technical facility and civic responsibility.
\end{abstract}

Keywords: Journalism Education; Web 2.0; Journalism Practice; Philosophy of Education; Citizen journalism

The Internet has become our medium for entertainment, communication, information, and socialization all rolled into one. In its latest incarnation, the web has lowered barriers to entry, providing services that are free and easy to learn, requiring minimal technical skills. With cloud computing, many expensive software have become superfluous. Smart phones and wireless technologies have further integrated these services into our lives. This has prompted some to gush that we are in the midst of an epochal change, comparable to the Gutenberg revolution (Naughton 2012); though there are reasons to be sceptical of such comparisons (Morozov 2013). But there is no denying that our dependence on technology and our access to information is unprecedented. In a connected world, we'll never suffer from a lack of information; but this can be a mixed blessing. But information saturation can be disempowering unless we have the capacity to process it into coherent ideas (Brabazon, 2007). Building this capacity will be the biggest challenge of classrooms in the digital age.

The general argument this article is that digital technologies are transforming both the institutions and practice of journalism. But journalism education has yet to fully catch up. Web 2.0 technologies present challenges, many unique to the field of journalism. But the opportunities they bring are greater. Journalism education will have to prepare students for both. The article relies on the author's 12-year experience as a new media practitioner and educator and discussions with academics in the field of journalism and media. It begins with a survey of the current media landscape and analyses the challenges that digital technologies pose to journalism and journalism education; it then uses Paulo Freire's concept of critical pedagogy to lay out the theoretical rationale for a new approach to journalism education. It ends with practical suggestions for integrating Web 2.0 technologies into classrooms. 


\section{The Challenge}

Historians, political scientists, sociologists and economists have all noted the challenges of working in a digital environment. But for journalism the concerns are more immediate. Journalists are in the business of news: and news is no longer the exclusive province of journalists. Any individual possessed of a computer, tablet, or smart phone with access to the Internet is a potential news producer. All disciplines are exposed to the disruptive influence of new communication technologies; but none is more vulnerable than journalism; none faces with greater urgency the need to adapt. A University of Maryland survey found high levels of anxiety among US journalists about future employment prospects (Wilson, 2008).

For the educator the challenges are different: one common to all humanities, the other specific to journalism. The first is epistemological: in a digital age, when the answer to everything seems one Google search away, what constitutes knowledge? The second is pedagogical: how must journalism education adapt to the diffusion of new technologies? Before addressing these questions however, it is important to take a survey of the current media landscape because, as Finberg (2012) notes, "the future of journalism education is linked to the future of journalism itself."

\section{The State of the Media}

For decades, scholars have raised alarms about the decline of diversity in media ownership. Bagdikian (2004) and McChesney (1999) have both noted how in just twenty years the ownership of American media went from fifty to six companies. Today a single new media company -- Apple dwarfs all six in market value. Google is worth more than Disney, Comcast and Viacom combined; Amazon is larger than NewsCorp and CBS put together; Facebook is as big as Time Warner. At a time when traditional media are beset by existential crises, new media are thriving. ${ }^{1}$ According to Pew's 2012 State of the Media Survey, during 2010-2011 where newspapers saw a 4 percent decline in readership, the web saw a 17.3 percent gain; where newspapers suffered a 7.3 percent loss in revenue, the web gained 23 percent. Traditional media are devoting new resources to online content; new media are crossing over into traditional domains. In 2011, ABC News announced that it would start providing video content for Yahoo News. Reuters announced it would develop original content for YouTube and will eventually host 10 original news shows. The Huffington Post has established its own 24-hour online news channel.

The future is clearly digital but there is more to the story. The Internet may have a much larger audience but the newsgathering resources and commitment to produce periodic content is still concentrated in the old media. A Reuters Institute for the Study of Journalism survey of media in eight countries across Europe, the Americas and Asia found that legacy media organizations with roots in print and broadcasting 'remain absolutely central to news provision' (Nielsen, 2012). This gives old media an advantage over Internet neophytes, since they can augment services by reproducing content online, repurposing it for the web, targeting specific audiences (Pavlik, 1996). Though the failures of traditional media are legion, audiences still expect them to maintain higher commitment to journalistic rigour, accuracy and credibility. People may read commentary on blogs but they still turn to traditional media for facts. Some blogs follow traditional practices such as source verification, fact checking, and data analysis; but audiences still don't credit news until it is confirmed by a mainstream source. It is unsurprising therefore that most of the top ranked news sites are attached to established brands such as the New York Times, the BBC, the Guardian or the Daily Mail. Political clout still resides in legacy media; their audiences are less fragmented. Still, it is 
undeniable that the proliferation of online news has impacted the style, craft, and business of journalism.

The State of Journalism

Technological progress has made the task of publishing progressively easier. User-based Web 2.0 technologies have redefined the relationship between producers and audiences. Consumers have become prosumers. Web 2.0 allows communication, contribution and collaboration, replacing the top-down models of the past with horizontal, peer-to-peer interactions. According to NM Incite, a Nielsen/McKinsey company, by the end of 2011, there were over 181 million blogs on the web, up from 36 million in 2006. This diffusion of online content producers has diminished the power of states and large media corporations to control information. If, according to Habermas, the old bourgeois public sphere had been inundated by mass media; the Internet is reincarnating a more democratic one in cybersphere (Habermas, 1962).

But where citizen journalism has enriched news, it has also devalued core journalistic skills and competencies (Wilson, 2008). Bill Keller, the executive editor of the New York Times, has lamented the decline of "quality journalism", which involved "experienced reporters going places, bearing witness, digging into records, developing sources, checking and double-checking, backed by editors who try to enforce high standards". This kind of journalism, he notes, was "hard, expensive, sometimes dangerous work" -- unlike blogging, which contains "countless voices riffing on the journalism of others but not so many that do serious reporting of their own" (quoted in Massing, 2009). New media's parasitic relationship with traditional media is also often lamented (Ibid). But less noted is the fact that traditional media increasingly rely on bloggers and social media to promote their content. Bloggers, when they are successful, get co-opted by the mainstream media; and the mainstream media, with all their resources, themselves exploit the blog format (Hull, 2007). Far from killing journalism, blogs may be reinvigorating it; they are a supplement rather than a substitute for traditional journalism. They are part of the same media ecology (Naughton, 2012).

As their own editors and publishers, bloggers can write without worrying about institutional filters (Weiss, 2007). But being one's own editor and publisher is a liberating experience; but for the novice such freedoms can sometimes spell disaster. The absence of an editor lifts constraints but it also removes an invaluable quality control mechanism. In countries like Britain, with restrictive libel laws, a single incautious remark could lead to ruin. Questions of law, ethics and politics haven't been made superfluous by the freedom and opportunities of the Internet. That is why, even as the news business struggles, journalism schools are thriving and student recruitment has remained high. Hanna and Sanders (2007) note that between 1994 and 2004, the number of full-time British students joining journalism programmes rose from 415 to 2,035. In the US, too, the need to develop tech skills to meet the demands of a changing industry is boosting recruitment (Flamm, 2013).

\section{The State of Journalism Education}

Laptops, tablets and mobile devices are already ubiquitous in classrooms; Google Glasses too will soon make cameos. The consequences of this are myriad. Teachers are no longer the only authorities in class; they have to compete with the Internet. This is not a problem specific to journalism: it affects every discipline. There are also cognitive effects: the kind of deep textual knowledge that came from students immersing themselves in their subjects is diminishing with myriad online references competing for students' attention (Brabazon, 2006; Carr, 2010). "Ease of 
use" has instead become the main criterion for students; and, as early as 2006, studies in Britain found 45 percent of students choosing Google as their primary research tool as compared to 10 percent for library catalogues (Griffiths \& Brophy, 2005). With Google, it is easy to believe that all knowledge is just a click away. But if Google can lead one to knowledge, given its PageRank system's susceptibility to manipulation, it can also mislead. Where questions of power are involved, it is inevitable that there will be attempts to amplify some viewpoints over others (Morozov, 2013).

Brabazon (2006, 2007), Sunstein (2007), Vaidhyanathan (2011) and Pariser (2011) have warned that the customization algorithms of portals like Google and Facebook can insulate users into bubbles. Though all ignore the fact that the filtering potential of these technologies is limited by the necessary openness of their architecture. The significant filters are not Google's or Facebook's; they are the ones that users themselves bring -- of ideology, socialization and prejudice: the so-called "confirmation bias" (Nickerson, 1998; Yoon, Sarial-Abi \& Gürhan-Canli, 2012). The chances of running into contrary opinion are not fewer on the Internet; they may well be higher (Shirky, 2011). It is a different matter if a user is predisposed to ignore such information. The abundance of information can also be a mixed blessing. On the one had it opens up new worlds of knowledge; on the other, it disempowers by allowing students to outsource mental activity. There is a tendency among Internet users to treat the web as a substitute rather than a supplement for memory; as an alternative, rather than an aid to critical thinking (Brabazon 2007; Carr 2010). Search engines make all knowledge appear within reach; the effort that goes into studying a subject, gathering facts, parsing information, and processing it into useful knowledge often seems superfluous. This outsourcing of mental activity encourages intellectual laziness and the distinction that Carr (1961) drew between facts and interpretations is being lost. Information is often confused for knowledge (Vaidhyanathan 2011). And in the data-information-knowledge-wisdom hierarchy (Lih, 2004), wisdom becomes remoter when knowledge has itself become fallible and information is little more than "the mindless and meaningless collection of data" (Frické 2009).

"Faced with an overload of information from a variety of partisan and non-partisan sources," write Carpenter \& Drezner (2010), students often "struggle to differentiate facts from propaganda, research from advocacy, and hard reportage from yellow journalism." A further distortion is introduced by the "algorithmic paternalism" of the personalization mechanisms used by Google and other web services (Pariser, 2011). The Internet can enlighten, but it can also reinforce error; it can voice inconvenient truths, but also purvey convenient falsehoods; it may hold a trove of information, but it is also a running sewer of lies, misinformation, slander and propaganda. If one is uncritical, this can confound skepticism, preclude further enquiry, and confine everyone to the ghettoes of their own prejudice.

There is also the question of technical proficiency. The practical side of the craft is taught in many journalism schools by print or broadcast veterans. They graft the online component as an extension to existing media. Stories produced for one medium are simply replicated in another. The limitations of one medium are thereby imposed on another and the distinctive features of the new are left unexplored. Further rigidity is imposed when courses in digital technologies are taught by nonpractitioners. Given the pace of technological change, academic knowledge always lags behind the state of the art (Bhuiyan, 2010). Only practitioners are able to stay on the cutting edge. This awareness has led enterprising educators like the New York University's Jay Rosen to start initiatives such as Studio 20, an experiment in project-based learning where students collaborate with teachers 
and practitioners on real-world editorial and web development assignments. As students acquire greater proficiency they graduate to their own individual projects. ${ }^{2}$

In a field where barriers to entry have been lowered, rigour, versatility, discipline and style could set one apart from the crowd; but little of it would matter without public consciousness. If professional journalism has suffered at the hands of citizen journalists; it is only partially because of technology. The main reason people turn to alternatives sources, from the whistleblowing Wikileaks to the news satirist Jon Stewart, is that they expect them to be less cozy with power, more critical, and more aware of civic responsibility. ${ }^{3}$ A 2010 survey by Pew's Internet \& American Life Project found that 69 percent of respondents followed news out of a "civic obligation to stay informed". Facility with digital technologies could certainly enhance one's employability but one's relevance will depend largely on one's willingness to monitor the centres of power. Beyond ensuring technical proficiency, analytical skills, and communicative excellence, it remains the responsibility of journalism schools to inculcate this ideal. Technical skills are useful to the extent that they aid the production of compelling journalism. Emphasis on what Brabazon (2007) calls 'operational literacy' cannot be allowed to overshadow the primacy of 'critical literacy'. True understanding will remain elusive until learners, to paraphrase Socrates, have gained knowledge of their own ignorance.

\section{Critical pedagogy 2.0}

In his influential tract Pedagogy of the Oppressed (1970), the Brazilian educator and theorist Paulo Freire highlights the shortcomings of what he called the "banking model" of traditional pedagogy that treats students as empty receptacles to be filled by what educators consider useful knowledge. Freire instead posited the idea of a dialogical pedagogy in which learners would be invested in their own education by participating in and contributing to the process of knowledge acquisition. Freire's critical pedagogy was part of a political project with revolutionary aims. But his ideas can also be transposed to a technological context with civic aims. Adapted to an educational field transformed by Web 2.0, they respond well to its disruptive changes. The social consciousness in these ideas may also help invigorate the civic purpose of journalism as a vigilant fourth estate. They also accord with research that has long shown that retention of knowledge is much higher in participatory forms of learning where students are actively engaged (Dale, 1969). ${ }^{4}$

As education struggles to keep pace with technology, teachers may not always be the savviest users of new media; it is possible that as "digital natives", students might have greater mastery of technology. Many practitioners of old media have avoided digital technologies lest it expose their limitations. But instead of seeing new media as a threat, educators can use students' specialist knowledge to enhance the learning experience. This shift in the balance of knowledge can be embraced and integrated into a new form of learning. Jay Rosen's Studio 20 is an ingenious attempt at this: but a similar approach can be integrated into journalism education more broadly. Web 2.0 technologies furnish all the tools that might be necessary for Project-Based Learning and Cooperative Learning (Newell, 2003).

As Ravitch (2012) notes, technology allows a more student-centric approach to learning in which students are able to engage far beyond the power of textbooks. Indeed, they could even bring their own technical proficiency to bear on the tasks at hand. Technology renders obsolete the old competitive models of education. The success of most Web 2.0 technologies is predicated on the notion of social production. Competitive models of assessment will have limited purchase in 
classrooms where the emphasis is on collaboration, synthesis and problem solving, and ingenuity and inspiration are released from solitary confinement. Traditional modes of assessment, with their emphasis on memorization and basic skills, will also have to be replaced by systems like Authentic Assessment (Hart, 1994; Wiggins, 1998), which measures students' ability to tackle complex realworld challenges through critical thinking and the creative application of acquired knowledge.

In their study of digital technologies in education, Collins and Halverson (2009) celebrate the greater individualization and customization that new technologies allow in classes; but they also warn against administrators' tendency to impose greater standardization and rules. A critical pedagogical model militates against such strictures. "Education is not the transmission of information or ideas," writes Hieronymi (2012). "Education is the training needed to make use of information and ideas." Collins and Halverson (2009) compare the transformations wrought by the digital revolution to those that accompanied the industrial revolution, when apprenticeship was replaced by universal schooling. Technology has relayed education to its third phase, they argue: to that of lifelonglearning. Pedagogy has proceeded from apprenticeship to didacticism to interaction; assessment from testing back to observation.

Pace Freire, however, the expositive method still retains its relevance: it is indispensable to the teaching of theory, history, ethics and law. But for teaching craft and skills, the imperative of an interactive method has never been greater. Journalism education can only be relevant if it integrates new technologies into the delivery of its concepts. Web 2.0 technologies in particular help address both its epistemological and pedagogical needs. Web 2.0 based learning lets students proceed from passive acquisition to active participation. Instead of merely receiving information from the top down, it enables a horizontal exchange of ideas. It engages students, involving them in their own education. It also helps build communities of intellectual affinity through which fresh ideas may be exchanged and synergistic collaboration made possible. Cloud-based technologies have further enhanced the potential of Web 2.0 as a pedagogical enabler, offering increased automation and a greater capacity to merge technologies. This ensures that practitioners are detained less by the technical nitty-gritty of the platforms than their potential for journalistic production.

The challenge of inculcating the values of accuracy, objectivity and rigour in students is greater in a digital era when everyone is looking for-and often finds-pre-processed answers. It therefore becomes imperative for classrooms to focus on the process rather than outcomes. An answer should be less important than the thinking that leads to it. It must demonstrate analytical rigour and methodological discipline. Student's minds must be exercised in the same way athletes are prepared for competitions. "Educators are coaches, personal trainers in intellectual fitness", writes Hieronymi (2012). "Just as coaching requires individual attention, education, at its core, requires one mind engaging with another, in real time: listening, understanding, correcting, modeling, suggesting, prodding, denying, affirming, and critiquing thoughts and their expression." It is not enough to convey vocational skills, she argues. "Education matters because ideas matter".

Facility with technology will liberate the mind to focus on the craft; it will enhance versatility and make the tools subservient to the task. Rather than imposing the limitations of one medium on another, a versatile journalist could transpose their advantages. Print's need for economy, for example, can be put to successful effect online. For a long time, as the original medium of news, print provided a useful basis for the teaching of journalism. Now, with the ascent of digital and the 
emergence of myriad media, no single technology enjoys primacy. A savvy journalist can make technology serve the story, finding new, non-linear, immersive forms. If this article is risking obsolescence by prescribing two specific technologies, it is because of the presumption that the concepts involved are of more enduring significance. The first tool is chosen because it best responds to the epistemological question and the second because its versatility allows for the development of the widest range of journalistic skills. Together they furnish the most flexible tools for a critical pedagogy.

\section{Using Wikis}

One phenomenon that nearly every educator has to deal with on a regular basis is Wikipedia. Alexa.com ranks it as the world's sixth most visited website. Among browsing locations, Alexa lists 'schools' as accounting for the highest numbers of visitors relative to the general Internet population. Its most frequent users are between the ages of 18-24, studying at graduate level. There is no greater temptation for a student in a rush to produce assignments than to cut corners by turning to Wikipedia. But what seems like a godsend often ends up as a trap. Wikipedia's open, collaborative, impermanent nature means that it can be a priceless resource; but not a source. It is a good place to begin one's research; but not the place to end it. If one accepts its limitations and compensates for them in further inquiry and cross-referencing, Wikipedia can be indispensable. Its coverage is far more comprehensive than of any existing encyclopedia, and its entries more recent. At the time of writing, Wikipedia's English edition alone has over 4.11 million articles.

Contrary to popular belief, Wikipedia hasn't made truth relative or perishable. A 2006 survey by Nature magazine comparing science articles on Wikipedia with the venerable Encyclopaedia Britannica found that 'the average science entry in Wikipedia contained around four inaccuracies; Britannica, about three' (Giles, 2005). This does not mean however that the differences are trivial: Britannica follows a rigorous editing process and entries are written by specialists; on Wikipedia virtually anyone can edit. Also, science articles might offer a methodologically more robust basis for comparison since scientific facts are less open to interpretation; but a comparison of articles on history, politics or art might yield very different results. On controversial issues, despite the democratic conception of Wikipedia, laws of power often assert themselves. ${ }^{5}$ To appreciate the value of Wikipedia, it is necessary to understand that the same openness that makes it a lively, constantly evolving repository of information also accounts for its susceptibility to vandalism. Britannica may be more accurate; but, given its editorial strictures, it can never be up to date. Its entries are closed, which make them referenceable; but they also make it static, less responsive to new knowledge. Wikipedia is a triumph of social production, a most spectacular manifestation of the open-source model that will likely govern the future of knowledge production. It also creates unique opportunities for participatory journalism with the potential for collaboration across regions over time (Bowman \& Willis, 2003)

There is no better way to acquaint students with the benefits and drawbacks of Wikipedia than to let them participate in Wiki-based collaborative projects. The logistics are easy. In the past one had to install a bespoke Wiki, hosted on a dedicated server. Now it can all be done using cloud based technologies. Wikispaces, PB Works and WetPaint Central all offer Wiki services that can be set up with minimum hassle. They also enable multi-media collaboration. Tools like VoiceThread that allow collaborative work on multimedia slideshows can further enhance the process of learning and sharing. ${ }^{6}$ Wikis may be used to assign groups of students collaborative research projects; these 
might relate to issues of contemporary relevance. Students can, for example, investigate the actors who are shaping debates on climate change or national security by looking at the authorities most often cited by the media, developing profiles on them, checking their sources of funding, identifying potential conflicts of interest (Miller \& Ahmad, 2010). Besides the potential synergies such assignments will also give students experience in editing, researching, fact-checking, and referencing; it will also provide opportunities for giving and receiving peer feedback. The process for negotiating content, write Forte \& Bruckman (2006), also includes such features of knowledge building discourse as "proposing new ideas, requesting evidence, and synthesizing divergent points of view".

The "history" tab on the standard Wiki enables both teachers and students to monitor and assess contributions. The ease with which Wikis are edited and manipulated gives students a better understanding of the merits of Wikipedia, its vulnerabilities, its uses and misuses, and its value as a tool for collaborative knowledge production. Its built-in system of peer-review also helps improve reasoning and writing (Forte \& Bruckman, 2006). The epistemological question - what constitutes knowledge - is sometimes best answered by participating in producing it. Wiki-based projects initiate students into the world of technologically enhanced learning without making them dependent on it.

\section{Using Blogs}

Sociologist C. Wright Mills (1959) described research as a 'craft', a descriptor that might also be applied to journalism. For Mills, first among the instruments of intellectual production was the 'file' for the researcher to capture every "fringe-thought, idea, snatches of a conversation, even a dream". "Once noted," he added, "these may lead to more systematic thinking, as well as lend intellectual relevance to more directed experience". For Carpenter and Drezner (2010), a blog "acts as a de facto online notebook for nascent ideas and research notes", as "an intellectual fishing net, catching and preserving the embryonic ideas that merit further time and effort...to link and critique news stories, research monographs, and other online publications." And, "because many blogs are archived and easily searchable", they note "authors can quickly retrace their thoughts online." The research and learning potential of blogs is immense (Deitering \& Huston, 2004; Oravec 2003).

The imperatives of news publishing are different than those of sociological research; the time scale is more compressed. But journalism too is an art of collecting information fragments and developing them into compelling stories. This requires intellectual discipline and methodological rigour. It also requires an inquisitive mind vigilant for story materials. As Mills (1959) suggested of researchers, a journalist's mind "must become a moving prism catching light from as many angles as possible". Blogs allow one to collect and organize information in various categories, while at the same time creating a forum for interaction where ideas can be tested and developed. Readers sometimes challenge or supplement the information and often furnish new leads, useful links and story ideas. Interactions between bloggers could likewise lead to synergy and stimulation. New connections might also be formed through blogrolls that help create virtual communities of elective affinity. The openness of the Internet allows blog interactions across disciplines, drawing journalists and academics out of their intellectual ghettoes, creating a more lively and instantaneous system of peer review (Carpenter \& Drezner, 2010).7 A blog also serves as a portfolio of one's work, bringing publication opportunities, from newspapers, magazines and book publishers. It can serve as a platform for book, film, or concert reviews. If one is able to demonstrate sufficient degree of 
expertise on a subject, it can also lead to invitations from television and radio channels (Stelter, 2006).

The benefits of blogs are obvious; as early as 2002, institutions such as the University of CaliforniaBerkeley integrated them into curricula. But many such courses teach about blogs rather than teach with them (Lum, 2005). It is in the practice of blogging, in the common pitfalls that the best learning opportunities lie. The demand for instant reaction to events usually means that reflection, accuracy and writing quality are often sacrificed. And with the exception of specialist blogs, most social media practitioners are caught in an eternal present, with little concern for history or context. But before journalists set off into the world, classrooms can use teachers' authority and peer judgment to constantly assess students' output, helping them overcome such errors, turning rigour, accuracy, and style into second nature. Beyond teaching students blogging best practices, the significance of style and tone (Hull, 2007), teachers can turn classrooms into fora for critical interaction both with students and between them. Projects can sometimes be initiated by teachers, sometimes by students: the more timely and proximate the issue, the higher usually is student motivation. Motivation is further boosted when the issue has a public interest angle. Local government is an important source of such stories; it helps students understand political issues in microcosm, develop civic consciousness, and gain experience in developing sources, accessing public records, and making use Freedom of Information requests.

An important way to learn good journalism is to understand what it isn't. One reason for the popularity of blogs is the real or perceived failure of mainstream journalism. Many blogs have started as fora for media critique. They challenge the mainstream media on facts, framing, and agenda setting. This could serve as an important pedagogical tool. It will make students more conscious of journalistic errors and less prone to repeating them. The demands of producing informed commentary on daily news would also encourage students to read more and be reflective and critical. It will educate them in the art of deconstructing arguments and more painstaking in the construction of their own. Assignments could include investigations into issues of contemporary relevance with the expectation that all key assertions will be substantiated with hyperlinks. Such assignments are useful in helping students assess the validity and reliability of sources while also being conscious of their durability on a notoriously ephemeral medium. It will help students understand the perishable nature of a lot of the information available on the Internet. It might also encourage them to understand the proper use of Wikipedia, when to use it as a source, when as a resource.

Blogs might also help students develop skills that are independent of media. Among these, writing is perhaps the most important. Blogging on a regular basis can help students work the fat off their writing, find a tone, and develop a voice (Hull, 2007). Blogging demands a leaner, more direct and concise prose - a style that can be useful to a journalist working in any medium. Blogs also create room for enhancing storytelling by integrating other technologies. Dull data can be brought to life with various forms of visualizations that new technologies make possible, ranging from static graphs and charts to interactive media. They can be used to summarize and visualize data and weave them into multi-media stories. Students with the capacity to turn data into graphs and charts consequently also develop the capacity to cast a critical eye on those of others. Students can exploit the web's capacity for non-linear presentation and also develop an intuitive sense of information 
architecture that allows news to be presented and categorized in an engaging and user-friendly manner.

\section{Conclusions}

Digital technologies are here to stay and every journalist will have to contend with them. The sooner this is done the better. It has implications not only for journalists, but also for the future of the trade. Technology can no longer be confined to specialized courses. It needs to be integrated into journalism education. Journalism training will have to emphasize the rudiments of the trade writing, research, analysis, ethics - without attaching it to a specific media. Instead of isolating "online" as a separate sphere, it will have to be integrated into a multimedia curriculum that focuses on the distinctive publishing features of each medium (Yau \& Al-Hawamdeh, 2001). To best exploit the synergy of the different media, students will need robust training in each; but since youth are often savvier users of new technologies, such training could benefit both from teachers' knowledge and students' experience.

Print remains a good basis for developing reporting, writing and storytelling skills; for learning the rigours of sourcing, verifiability, economy, accuracy, fairness and objectivity. To expand the repertoire, however, progressively more elements could be added to stories, from images, graphics, sounds to video. Students may be encouraged to experiment with form and structure, finding new, non-linear modes of story-telling. For effective multimedia storytelling, they will need core skills in audio and video production, graphics and image editing, data visualization and content management. But beyond tools, the determinants of compelling journalism will remain the same: civic consciousness, professional integrity, and sociological imagination. Journalism education would have achieved little if, focusing primarily on skills, it fails to encourage what Brabazon (2007) calls "cycles of reflection."

To truly harness technology for journalism, students will have to be both distanced from and immersed in it. Teachers will have to use their authority to turn classrooms into a space where students can step back and reflect on the information they have imbibed. At the same time students must have a robust enough training in digital technologies to know their promises and limitations. Only in this way will they gain the intellectual confidence and technical skills necessary to produce useful knowledge amid information excess. Wikis can help students hone their writing skills, thinking through issues, turning information into knowledge. Blogs will help students enhance their storytelling abilities, integrating multi-media, and experimenting with new, non-linear structures and forms. Research has long shown that the process of writing helps students think through issues, reflecting on what they know and integrating it with new knowledge (Emig, 1977). Project based learning will also enhance motivation and consolidate learning outcomes (Newell, 2003).

Technology makes many things easier; but it does not obviate civic consciousness, critical thinking, analytical skills, tenacity, rigour, and imagination. The foremost challenge for educators will be to disabuse students of the notion that successful journalism can be done on the cheap. Technology is an enabler of journalism; it makes research and publishing easier; but it can also make journalism better and story-telling richer. Besides its many other promises, technology enables students to take ownership of their own learning. It opens new pedagogical vistas, writes Ravitch (2012), "demonstrating how learning can become challenging, turning learners into explorers, researchers, voyagers, adventurers". 
From Huxley to Postman to Morozov, there have been many warnings against technology's dark side. It is important therefore that in relaying all the promises of technology, educators do not fail to also highlight its limitations and vulnerabilities. But so long as one is mindful of them, a brave new world need not be a nightmare; it may actually be a better world. Journalism can only gain if the extremes of technophobia and technophilia are replaced with a critical pedagogy that keeps its social function and civic consciousness foremost.

\section{References}

- Bagdikian, B. H. (2004). The New Media Monopoly. Boston: Beacon Press.

- Bhuiyan, S.I. (2010). Teaching media convergence and its challenges. Asia Pacific Media Educator. pp. 115-122.

- Brabazon, T. (2006) The Google Effect: Googling, Blogging, Wikis and the Flattening of Expertise. Libri, 56. pp. 157-167.

- Brabazon, T. (2007) The University of Google: Education in the (Post) Information Age. Aldershot, U.K.: Ashgate.

- Bowman, S. \& Willis, C. (2003). We Media: How audiences are shaping the future of news and information. The American Press Institute.

- Carpenter, C. \& Drezner, D.W. (2010). International Relations 2.0: The Implications of New Media for an Old Profession. International Studies Perspectives, 11. pp. 255-272

- Carr, E.H. (1961). What is History? London: Penguin.

- Carr, N.G. (2010). The Shallows: What the Internet Is Doing to Our Brains. W. W. Norton.

- Collins, A. \& Halverson, R. (2009). Rethinking Education in the Age of Technology: The Digital Revolution and the Schools. New York: Teachers College Press.

- Dale, E. (1969). Audio-Visual Methods in Teaching. Third Edition. New York: Holt, Rinehart \& Winston.

- Deitering, A. \& Huston, S. (2004). Weblogs and the "Middle Space" for Learning. Academic Exchange Quarterly. 8, 4. pp. 273-278.

- Emig, J. (1977). Writing as a mode of learning. College Composition and Communication. 28, 2. pp. $122-128$.

- Flamm, M (2013). Journalism's decline boosts j-schools. Crain's New York Business. http://www.crainsnewyork.com/article/20130405/MEDIA ENTERTAINMENT/130409909

- Finberg, H. (2012). Journalism education cannot teach its way to the future. Poynter.

- http://www.poynter.org/how-tos/journalism-education/177219/journalism-educationcannot-teach-its-way-to-the-future/

- Forte, A. \& Bruckman, A. (2006). From Wikipedia to the classroom: exploring online publication and learning. International Society of the Learning Sciences.

- http://www.cc.gatech.edu/ asb/papers/forte-bruckman-icls06.pdf

- Freire, P. (1970). Pedagogy of the oppressed. New York: Herder and Herder.

- Frické, M. (2009). The knowledge pyramid: a critique of the DIKW hierarchy. Journal of Information Science. 35, 2. pp. 131-142.

- Giles, J. (2005) Special Report: Internet Encyclopaedias go head to head. Nature, 438. pp. 900-901.

- Griffiths, J.R. \& Brophy, P (2005). Student Searching Behavior and the Web: Use of Academic Resources and Google. Library Trends. 53, 4. pp. 539-554. 
- Habermas, Jürgen (1962 trans 1989) The Structural Transformation of the Public Sphere: An Inquiry into a category of Bourgeois Society. Cambridge.

- Hanna, M. \& Sanders, K. (2007). Journalism Education in Britain: who are the students and what do they want? Journalism Practice. 1, 3. pp. 404-420.

- Hart, D. (1994). Authentic Assessment: A Handbook for Educators. Dale Seymour

- Head, A. J. (2007). Beyond Google: How Do Students Conduct Academic Research? First Monday 12, 8. http://firstmonday.org/article/view/1998/1873

- Hieronymi, P. (2012). Don't Confuse Technology With College Teaching. The Chronicle of Higher Education. http://chronicle.com/article/Dont-Confuse-Technology-With/133551/

- Hull, D. (2007). Blogging Between the Lines. American Journalism Review. http://www.ajr.org/Article.asp?id=4230

- $\quad$ Lanchester, J. (2010). Let us pay. London Review of Books. 32, 24. pp. 5-8.

- Lih, A. (2004). Wikipedia as Participatory Journalism: Reliable Sources? Metrics for evaluating collaborative media as a news resource. 5th International Symposium on Online Journalism. April 16-17. University of Texas at Austin. http://www.ufrgs.br/limc/participativo/pdf/wikipedia.pdf

- Lum, L. (2005). The rise of blog nation. Diverse Issues in Higher Education. http://diverseeducation.com/article/4601/

- Massing, M. (2009). The News about the Internet', New York Review of Books. 56, 13. http://www.nybooks.com/articles/archives/2009/aug/13/the-news-about-the-internet/

- McChesney, R.W. (1999). Rich Media, Poor Democracy: Communication Politics in Dubious Times. Urbana and Chicago: University of Illinois Press.

- McLuhan, M. (1964). Understanding Media: The Extensions of Man. McGraw-Hill.

- Miller, D. \& Ahmad, M.I. (2010). Powerbase: A collaborative resource for monitoring power networks. Radical Statistics. 102. pp. 4-16.

- Mills, C.W. (1959) The Sociological Imagination. London: Oxford University Press.

- Naughton, J. (2012). From Gutenberg to Zuckerberg: What You Really Need to Know About the Internet. Quercus.

- Newell, R.J. (2003). Passion for Learning: How Project-based Learning Meets the Needs of 21st Century Students. Scarecrow Press.

- Nickerson, R. S. (1998). Confirmation Bias; A Ubiquitous Phenomenon in Many Guises. Review of General Psychology. 2, 2. pp. 175-220

- Nielsen, R. K. (2012). Ten Years that Shook the Media World: Big Questions and Big Trends in International Media Developments. Reuters Institute for the Study of Journalism. https://reutersinstitute.politics.ox.ac.uk/fileadmin/documents/Publications/Working Paper s/Nielsen - Ten Years that Shook the Media.pdf

- Oravec, J.A. (2003). Blending by blogging: weblogs in blended learning initiatives. Journal of Educational Media. 28, 2-3. pp. 225-233.

- Pariser, E. (2011) The Filter Bubble: What the Internet Is Hiding from You, New York: Penguin Press.

- Pavlik, J. (1996). New Media Technologies. Boston: Allyn and Bacon.

- Ravitch, D. (2012). The promise and perils of technology in education. 2012 Annual CUE Conference. Palm Springs. http://www.youtube.com/watch?v=pMinNm80bMw 
- Shirky, C. (2011). Political Power of Social Media-Technology, the Public Sphere Sphere, and Political Change. Foreign Affairs. http://www.foreignaffairs.com/articles/67038/clayshirky/the-political-power-of-social-media

- Sunstein, C. (2007) Republic.com 2.0. Princeton, NJ: Princeton University Press.

- Vaidhyanathan, S. (2011). The Googlization of Everything: And why we should worry. Berkley: University of California Press.

- Weiss, P. (2007). Mondoweiss, Chapter One. The American Conservative. June 4. http://www.theamericanconservative.com/articles/mondoweiss-chapter-one/

- Wiggins, G. P. (1998). Educative assessment: Designing assessments to inform and improve student performance. San Francisco: Jossey-Bass Publishers.

- Wilson, K. (2008). High Anxiety. American Journalism Review. http://www.ajr.org/Article.asp?id=4478

- Yau, J.T.K. \& Al-Hawamdeh, S. (2001). The Impact of the Internet on Teaching and Practicing Journalism. The Journal of Electronic Publishing. 7, 1.

http://quod.lib.umich.edu/cgi/t/text/textidx?c=jep;view=text;rgn=main;idno=3336451.0007.102

- Yoon, Y., Sarial-Abi, G. \& Gürhan-Canli, Z (2012). Effect of Regulatory Focus on Selective Information Processing. Journal of Consumer Research. 39, 1.

http://papers.ssrn.com/sol3/papers.cfm?abstract id=1888686

\footnotetext{
${ }^{1}$ Figures acquired through Yahoo Finance on 25 March 2013.

2 http://journalism.nyu.edu/graduate/courses-of-study/studio-20/

${ }^{3}$ A 2009 Time magazine poll found Jon Stewart to be the "most trusted newsperson in America".

${ }^{4}$ See 'cone of experience', p. 108, in Dale (1969).

${ }^{5}$ Organized groups often try to skew Wikipedia's coverage along the lines of their political agenda. A striking instance of this was revealed when the pro-Palestinian website Electronic Intifada obtained emails sent by the pro-Israel advocacy group CAMERA laying out a strategy for skewing Wikipedia's coverage in Israel's favour. The emails included advice for advocates on gaining the endorsements of editors so that they could become 'uninvolved administrators' who could then be called in to arbitrate editing disputes. 'One or more of you who want to take this route,' the email advised, 'should stay away from any Israel realted [sic] articles for one month until they interact in a positive way with 100 wikipedia editors who would be used later to vote you as an administrator.' See: 'El exclusive: a proIsrael group's plan to rewrite history on Wikipedia' The Electronic Intifada, 21 April 2008 ${ }^{6}$ http://www.wikispaces.com; http://voicethread.com; http://pbworks.com; and http://www.wetpaintcentral.com

${ }^{7}$ Other disciplines are already benefitting from the peer feedback possibilities of blogs. See for example Jess Moriarty and Vy Rajapillai's case study, Using Blogs for Peer Feedback in a Creative Writing Course - An Exploratory Study', The Higher Education Academy English Subject Centre, accessed 14 February 2010.
} 